\title{
Treatment of pulmonary hypertension in idiopathic pulmonary fibrosis: shortfall in efficacy or trial design?
}

This article was published in the following Dove Press journal:

Drug Design, Development and Therapy

2 July 2014

Number of times this article has been viewed

\section{Steven D Nathan \\ Christopher S King}

Advanced Lung Disease Clinic, Inova Fairfax Hospital, Falls Church, VA, USA
Correspondence: Steven D Nathan Advanced Lung Disease and Transplant Program, Inova Fairfax Hospital, 3300 Gallows Road, Falls Church, VA 22042, USA

Tel +I 7037763610

Fax +I 70377635 I5

Email steven.nathan@inova.org
Abstract: Idiopathic pulmonary fibrosis (IPF) is a disease that carries a high mortality. Pulmonary hypertension (PH) frequently complicates the course of patients with IPF and is associated with significantly worse outcomes. Whether $\mathrm{PH}$ is a surrogate or driver of these worse outcomes remains unanswered, but the presence of $\mathrm{PH}$ represents an attractive target for therapy. This review delves into the various pulmonary vasoactive agents that have been subjected to study in IPF, the pitfalls of some of these prior studies, and attempts to lay a foundation for future study designs targeting PH in IPF.

Keywords: phenotype, interstitial lung disease

\section{Introduction}

There is a growing appreciation that pulmonary hypertension $(\mathrm{PH})$ complicates the course of patients with many forms of advanced lung disease, including those with interstitial lung disease. ${ }^{1}$ These patients are generally included within group 3 under the World Health Organization (WHO)'s five-group categorization of PH. ${ }^{2}$ Idiopathic pulmonary fibrosis (IPF), one of the broad group of interstitial lung diseases and the prototype form of the idiopathic interstitial pneumonias, is commonly complicated by the presence of $\mathrm{PH}^{3}$ IPF tends to occur in the elderly and is slightly more common in males compared with females. It is estimated that there are anywhere from 100,000-200,000 patients with IPF in the United States, but it is a disease that occurs throughout the world without a particular ethnic propensity. ${ }^{4}$ There is also evidence, both in the United States and Europe, to suggest the incidence is increasing. ${ }^{4}$ Whether this is due to increased awareness, greater number of computed tomography (CT) studies of the chest being performed, an increasingly elderly population, or a true increased incidence is uncertain.

IPF is associated with significant risk of comorbidities and mortality. ${ }^{5,6} \mathrm{PH}$ frequently complicates the course of patients with IPF, with a reported wide prevalence range of $10 \%-86 \%{ }^{1}$ Amongst other comorbidities, IPF patients have an increased prevalence of thromboembolic disease and sleep disordered breathing, as well as coronary artery disease, all of which can contribute to underlying PH. ${ }^{5}$ The median survival of patients with IPF is reported to be $2.5-5$ years. ${ }^{7}$ Those patients who have complicating PH tend to have significantly worse outcomes, not only in the form of an increased risk of mortality but also, from a functional limitation standpoint. PH complicating IPF is associated with reduced exercise ability, evidenced by both a decreased distance and increased oxygen desaturation. ${ }^{8}$ One study demonstrated that 
IPF patients with $\mathrm{PH}$ documented via right heart catheterization had a 1-year mortality of $28 \%$ versus those without $\mathrm{PH}$, whose 1-year mortality was only $5.5 \% .^{8}$ In two studies of IPF, patients with echocardiographic evidence of $\mathrm{PH}$, those with right ventricular systolic pressures greater than or equal to 50 or $60 \mathrm{mmHg}$, respectively, had 1-year mortality in excess of $50 \% .^{9,10}$ The pathogenesis of PH in IPF is complex and incompletely understood. It was long thought that PH in IPF was attributable to hypoxemic vasoconstriction and destruction of the pulmonary capillary bed by fibrosis. While these mechanisms likely contribute to the development of $\mathrm{PH}$ in IPF, it is now believed that other mechanisms are at work as well. These include alterations in the balance of angiogenesis and increased production of profibrotic mediators that lead to $\mathrm{PH}$, including leukotrienes, tumor necrosis factor- $\alpha$, platelet-derived growth factor, fibroblast growth factor, and endothelin-1. ${ }^{11}$ A complete review of the epidemiology, diagnostic evaluation, and pathogenesis of $\mathrm{PH}$ in IPF is beyond the scope of this article. Interested readers are referred to a recent review by our group on the topic. ${ }^{11}$

What remains unclear is whether or not $\mathrm{PH}$ is an adaptive phenomenon and a surrogate for other deleterious aspects of the disease. Although it is clearly associated with worse outcomes, it remains unproven that treating $\mathrm{PH}$ will result in improved outcomes. For example, if the $\mathrm{PH}$ was solely due to fibrous obliteration of the pulmonary vasculature, this would be an adaptive phenomenon and likely not a viable target for therapy. However, there is both physiologic and radiographic evidence of discordance between the fibrotic burden of disease and $\mathrm{PH}$, attesting to factors other than the fibrosis being involved. ${ }^{12,13}$ The reason why some patients develop PH that is apparently "disproportionate" to their underlying fibrosis is uncertain. The incompletely understood and likely complex pathogenesis, together with small series attesting to the utility of treating $\mathrm{PH}$ in IPF, provide a foundation and basis for further consideration of randomized controlled trials of pulmonary vasoactive therapies in this patient phenotype.

\section{Overview of studies}

Thus far, there have been a number of series examining pulmonary vasoactive agents in patients with IPF and other forms of fibrotic lung disease. Most of these series have been small and retrospective, with inherent associated limitations (Table 1). ${ }^{14-22}$ The largest, most robust study thus far has been the STEP-IPF study of sildenafil. This study included patients with advanced IPF and selected for patients with complicating $\mathrm{PH}$, by virtue of the inclusion criterion of a single breath diffusing capacity (DLCO) $<35 \%$ of predicted. ${ }^{15}$ Based on prior studies, it can be estimated that about $60 \%$ of these patients had $\mathrm{PH} .{ }^{12}$ The primary end point was a $20 \%$ increase in the six-minute walk test (6MWT) distance, which the study failed to meet. However, a number of secondary end points were positive, including differences in the change in quality of life measures, DLCO, and partial pressure of arterial oxygen (PaO2) favoring the treatment arm. Additionally, there was a trend towards a mortality benefit after 24 weeks of follow up, although the numbers were relatively small, with eleven deaths in the placebo arm versus four in the treatment arm $(P=0.07)$. A subsequent subgroup analysis of those patients with echocardiographic evidence of right ventricular dysfunction revealed a favorable effect in the treatment arm based on the 6MWT distance. ${ }^{23}$ Together with the primary data analysis, this provides proof of concept, attesting to the potential targeting of $\mathrm{PH}$ in patients with IPF.

The endothelin receptor antagonist group of agents has also been trialed in IPF. Most of the studies undertaken have not been directed to the PH complicating IPF but rather, have sought to test the antifibrotic effects of these agents. Bosentan was studied in 616 IPF patients in the BUILD3 study, which was a negative study based on the primary end point of IPF worsening or all-cause death. ${ }^{20}$ The Artemis-IPF study of ambrisentan was stopped early by the sponsor, for apparent lack of efficacy and suggestion of harm. ${ }^{21}$ The sister study to this (Artemis-PH), was geared specifically to IPF patients with $\mathrm{PH}$ diagnosed via right heart catheterization. This study was also stopped early, after a subgroup analysis of patients with PH from Artemis-IPF ( $10 \%)$ failed to demonstrate any positive signals. ${ }^{20}$ At the stop of the trial, the study was also underperforming in terms of recruitment, attesting to the difficulty of enrolling a patient population with a confident diagnosis of IPF and associated PH. Macitentan, a third endothelin receptor antagonist studied in IPF, also failed to meet its primary end point of change in the forced vital capacity (FVC), a surrogate for fibrosis. ${ }^{22}$

\section{Study design: PH and IPF}

There are many elements that require careful consideration in the design, conduct, and completion of a successful clinical trial. First, there must be a pathway, aspect, or consequence of the disease to target, with the potential to modify or alter patient outcomes in a salutary fashion. If it is a consequence of the disease that is being targeted, such as the PH that accompanies IPF, there needs to be a reasonable level of certainty that this is a deleterious consequence of the disease; in other words, a maladaptive rather than an 
Table I Case series and trials of vasodilator therapy in idiopathic pulmonary fibrosis

\begin{tabular}{|c|c|c|c|c|c|c|c|}
\hline $\begin{array}{l}\text { Type of lung } \\
\text { disease }\end{array}$ & Investigator & Year & Type of study & Number & Therapy & Results & Comments \\
\hline Lung fibrosis & $\begin{array}{l}\text { Ghofrani } \\
\text { et al }{ }^{16}\end{array}$ & 2002 & Open-label RCT & 16 & $\begin{array}{l}\text { Sildenafil, iNO, } \\
\text { epoprostenol }\end{array}$ & $\begin{array}{l}\text { Sildenafil improved } \\
\text { gas exchange }\end{array}$ & \\
\hline IPF & $\begin{array}{l}\text { Collard } \\
\text { et al }{ }^{17}\end{array}$ & 2007 & $\begin{array}{l}\text { Open-label, } \\
\text { prospective trial }\end{array}$ & 14 & Sildenafil & $\begin{array}{l}57 \% \text { had significant } \\
\text { increase in } 6 \mathrm{MWT}\end{array}$ & \\
\hline IPF & $\begin{array}{l}\text { Krowka } \\
\text { et al }{ }^{14}\end{array}$ & 2007 & $\mathrm{RCT}$ & 51 & Inhaled iloprost & $\begin{array}{l}\text { No improvement in 6MWT, } \\
\text { NYHA/WHO Class }\end{array}$ & Abstract only \\
\hline $\begin{array}{l}\text { IPF, CTD, } \\
\text { Sarcoid }\end{array}$ & Minai et $\mathrm{al}^{55}$ & 2008 & Case series & 19 & $\begin{array}{l}\text { IV epoprostenol, } \\
\text { bosentan }\end{array}$ & $\begin{array}{l}\text { Improvement in NYHA/ } \\
\text { WHO Class and 6MWT }\end{array}$ & $\begin{array}{l}8 \text { of } 19 \text { with IPF; } \\
6 \text { of } 8 \text { IPF patients } \\
\text { responded to therapy }\end{array}$ \\
\hline IPF & Raghu et al $\left.\right|^{56}$ & 2010 & RCT (BUILD-I) & 154 & Bosentan & $\begin{array}{l}\text { Minimal changes } \\
\text { in QOL and dyspnea }\end{array}$ & \\
\hline IPF & $\begin{array}{l}\text { Jackson } \\
\text { et al }{ }^{19}\end{array}$ & 2010 & $\mathrm{RCT}$ & 29 & Sildenafil & $\begin{array}{l}\text { No difference in } 6 \mathrm{MWT} \\
\text { or Borg score }\end{array}$ & \\
\hline IPF & IPFnet ${ }^{15}$ & 2010 & RCT (STEP-IPF) & 180 & Sildenafil & $\begin{array}{l}\text { No change in primary } \\
\text { outcome, } 20 \% \text { increase } \\
\text { in } 6 \mathrm{MWT}\end{array}$ & $\begin{array}{l}\text { Sildenafil improved } \\
\text { dyspnea, QOL, and } \\
\text { oxygenation }\end{array}$ \\
\hline IPF & King et $\mathrm{a}^{57}$ & 2011 & RCT (BUILD-3) & 616 & Bosentan & $\begin{array}{l}\text { Bosentan did not change } \\
\text { the time to clinical } \\
\text { worsening }\end{array}$ & $\begin{array}{l}2 \text { to I randomization } \\
\text { (407 bosentan, } \\
209 \text { placebo) }\end{array}$ \\
\hline IPF & Raghu et $\mathrm{al}^{21}$ & 2013 & RCT (ARTEMIS-IPF) & 492 & Ambrisentan & $\begin{array}{l}\text { Ambrisentan did not } \\
\text { reduce the rate of time } \\
\text { to disease progression }\end{array}$ & $\begin{array}{l}\text { Terminated early for } \\
\text { lack of efficacy and } \\
\text { suggestion of harm }\end{array}$ \\
\hline IPF & Han et $\mathrm{a}^{23}$ & 2013 & $\begin{array}{l}\text { Substudy of RCT } \\
\text { (STEP-IPF examining } \\
\text { patients with } \\
\text { echo data) }\end{array}$ & 119 & Sildenafil & $\begin{array}{l}\text { Improved QOL and } \\
6 \mathrm{MWT} \text { distance in patients } \\
\text { with RVSD treated with } \\
\text { sildenafil }\end{array}$ & \\
\hline $\begin{array}{l}\text { Pulmonary } \\
\text { fibrosis }\end{array}$ & Saggar et $\mathrm{al}^{28}$ & 2014 & $\begin{array}{l}\text { Open-label, } \\
\text { prospective }\end{array}$ & 15 & IV treprostinil & $\begin{array}{l}\text { Right heart hemodynamics } \\
\text { and echocardiographic } \\
\text { function improved without } \\
\text { affecting oxygenation }\end{array}$ & $\begin{array}{l}\text { Only enrolled } \\
\text { patients with } \\
\mathrm{mPAP} \geq 35 \mathrm{mmHg}\end{array}$ \\
\hline
\end{tabular}

Abbreviations: 6MWT, six-minute walk test; CTD, connective tissue disease; iNO, inhaled nitric oxide; IPF, idiopathic pulmonary fibrosis; IV, intravenous; mPAP, mean pulmonary artery pressure; NYHA, New York Heart Association; QOL, quality of life; RCT, randomized controlled trial; RVSD, right ventricular systolic dysfunction; WHO, World Health Organization.

adaptive response. Other important ingredients for success pertain to the properties of the drug; it needs to be effective, have an acceptable side-effect profile, be relatively easy to administer, have a favorable pharmacokinetic profile, and be deliverable to the intended targeted area in high enough concentrations to be effective.

Yet another hurdle in the design of any study is the choice of the correct patient population or disease phenotype. In the context of an IPF and PH study, this is especially difficult since there are two considerations that need to be balanced. The first is determination of the hemodynamic threshold, and the second is determination of the permissible degree of parenchymal disease. This raises the concept of disproportionate $\mathrm{PH}(\mathrm{DPH})$ in the context of parenchymal lung disease. Although use of this term is discouraged in the most recent $\mathrm{PH}$ guidelines, primarily owing to the lack of a clear definition, the concept still holds true. ${ }^{24}$ The inference of $\mathrm{DPH}$ is that it is more severe than the degree of parenchymal lung disease. By further extrapolation, it is the $\mathrm{PH}$ that might be considered the limiting factor in terms of the patient's symptoms and exercise tolerance, as well as the primary driver of outcomes. It is conceivable that there is no single threshold but rather, a variable pressure (or other parameter) based on the severity of the associated parenchymal lung disease. In other words, "one size might not fit all", and the threshold might depend on the characteristics and balance between the individual patient's parenchymal disease and pulmonary hemodynamic profile. Indeed, if one were to define a cutpoint, which parameter would best discriminate those patients in whom pulmonary hemodynamics dictate their clinical presentation and course? Would it be the mean pulmonary artery pressure (mPAP) that is used to define $\mathrm{PH}$, or the highest pressure generated, specifically the systolic PA pressure (sPAP), or the lowest pressure in the form of the diastolic PA pressure? Alternatively, should it be a deleterious consequence of PH that defines DPH, and should 
its occurrence suggest that therapy should be instituted? For example, is the $\mathrm{PH}$ only disproportionate if there is evidence of right heart decompensation, as reflected in a raised right ventricular diastolic pressure or elevated right atrial pressure, or should a reduced cardiac index be used to define the threshold that heralds the onset of DPH? One could argue that an elevated right atrial pressure or reduced cardiac index is a late manifestation and evidence of decompensation due to DPH and is therefore a downstream, late consequence rather than a threshold to define onset. However, in the context of a clinical trial, targeting a later-stage consequence might select for a population more likely to show benefit. As opposed to studies targeting earlier $\mathrm{PH}$, enrollment of patients with evidence of decompensated right ventricular (RV) function might also enable a shorter trial.

The case for the sPAP rather than mPAP can be made from echocardiographic series in which the sPAP appeared to delineate outcomes very well in a "dose proportionate" fashion..$^{9,10}$ This was found despite the well-recognized inherent inaccuracy of the echocardiographic estimated sPAP. ${ }^{25}$ It is unclear whether the elevated SPAP is a phenomenon that occurs as a primary vasculopathic effect of the disease or as a consequence of vascular ablation and the reduced vascular capacitance imparted by the surrounding fibrotic parenchymal disease. In the latter pathogenic scenario, the sPAP might then just be a surrogate of disease severity, rather than a determinant of disease severity. At this point in the disease course, it might still be the parenchymal disease that is driving outcomes, and DPH might not be reflected by the sPAP. It is conceivable that the PH complicating IPF is a biphasic syndrome where initially, as described above, $\mathrm{PH}$ is a secondary phenomenon; however, over time, the load imposed on the RV might ultimately result in RV dysfunction, at which point it is the RV that determines outcomes. Therefore it might be the measure of RV dysfunction that defines DPH. Supportive of this concept are data from a subgroup analysis of the Step-IPF study attesting to the efficacy of PH therapy, in the form of sildenafil, once RV dysfunction ensues. ${ }^{23}$ This paradigm would not be unique to IPF; specifically, it is well established in congestive heart failure and pulmonary arterial hypertension (PAH) that RV dysfunction drives outcomes. ${ }^{26,27}$ Therefore in the context of clinical trials of therapeutic agents for PH complicating IPF, some measure of RV dysfunction might be best to prime the population for a successful intervention. Whether this should be echocardiographic evidence of RV dysfunction or a hemodynamic parameter, such as the RV diastolic pressure, remains to be determined. At this point in time, this concept requires further validation, and pending further insight, it will likely remain that mPAP is the criterion used to define patients who are suitable for enrollment.

What threshold pressure measurement should be employed to determine enrollment in clinical trials? It is difficult to operationalize a "rolling" mPAP threshold based on other parameters, such as the severity of the parenchymal lung disease. It is therefore more pragmatic to have one pressure threshold. Should this be the traditional definition of $\mathrm{PH}$, namely an $\mathrm{mPAP} \geq 25 \mathrm{mmHg}$ or a higher pressure or perhaps even a lower threshold? The case for a higher threshold stems from the notion that the higher the pressure, the greater the likelihood of a response to PH therapy. While this concept is likely true, the downside of a higher threshold, is that fewer patients would qualify for enrollment, and this would preclude the opportunity to demonstrate benefit in patients with lower pressures. Further, if the participants prove difficult to recruit, this might place the study at risk of termination. This is especially pertinent in the context of an IPF study, where the other high "bar" to patient entry is the attainment of a confident IPF diagnosis. Two sequential high thresholds tend to be synergistic as impediments to study recruitment. From a pragmatic standpoint, the sponsoring company or agency might not want to pursue drug development if only a very small subset of patients is shown to benefit, as this might not be a commercially viable endeavor.

As was alluded above, the greater risk to derailment of any $\mathrm{PH} / \mathrm{IPF}$ study is incomplete recruitment, rather than a fully recruited study with a lesser chance of successfully meeting its primary end point. In this regard, a strong case can be made for studies of broader groups of patients with fibrotic lung disease. If a study allowed a broader group of fibrotic patients as the basis for recruitment, then a higher mPAP might not preclude successful recruitment. In such a study design, the concept of severe $\mathrm{PH}$, as defined in the most recent WHO guidelines (mPAP $\geq 35 \mathrm{mmHg}$ ), might be tested as a target for PH therapy - indeed, a recent study by Sagger et al employed this very approach. ${ }^{28}$ Such studies could include patients with any of the idiopathic interstitial pneumonias, as well as those with chronic hypersensitivity pneumonitis and occupational lung diseases, such as asbestosis. Another question that then arises regarding how broad a fibrotic population to allow. For example, should WHO group 5 patients, such as those with sarcoidosis, be eligible for enrollment? What of connective tissue disease patients who have interstitial lung disease that is "disproportionate" to their PH? It is the authors' opinion that these patients should not be included in such studies and that instead, patient participants be limited 
to either patients with interstitial lung disease who fall within WHO group 3 or to those with one of the idiopathic interstitial pneumonias. This should not dissuade the study of $\mathrm{PH}$ complicating sarcoidosis or other diseases, but such studies would be best served by limiting enrollment to the specific disease state resulting in $\mathrm{PH}$.

If the study is limited to a select group of patients, such as those with confirmed IPF, then employing mPAP thresholds even lower than the standard definition of PH might warrant consideration. Lower mPAP thresholds have been shown to differentiate patients with worse outcomes. ${ }^{29}$ Also, IPF patients with a propensity for $\mathrm{PH}$ tend to have progressively higher pressures over time, and sometimes this occurs in an accelerated fashion. ${ }^{30}$ Therefore, a lower threshold (such as mPAP of $20 \mathrm{mmHg}$ ) could conceivably produce a positive study result but would likely require a longer period of follow up to capture a difference between the groups.

While selection of the correct hemodynamic threshold is integral to the success of any $\mathrm{PH}$ study, so too is the selection of the permissible extent of the associated parenchymal lung disease. There might be a subgroup of patients whose pulmonary fibrosis is so severe that this drives their symptoms and outcomes. Therefore, these patients might not benefit from therapies directed at their PH. While this appears to make intuitive sense, this remains to be proven since the accompanying PH might still play a role in their ultimate demise. Nonetheless, it is unclear whether there should there be a lower limit on the percent predicted FVC and if so, what this should be. Indeed, it is unclear whether this is the best parameter whereby to judge the extent of the fibrotic process, as opposed to CT appearance and an objective computer-based scoring algorithm. The variable extent of the fibrotic process raises the concept, once again, of a flexible hemodynamic threshold; the worse the extent of the fibrosis, the higher the hemodynamic "bar" for study entry.

What of ventilation/perfusion (V/Q) mismatching with pulmonary vasoactive agents? Any pulmonary vasodilator has the propensity to worsen V/Q matching, by dilating vessels perfusing poorly ventilated lung units. However, it is conceivable that patients might feel and do better, despite associated increased desaturation, if there is a favorable hemodynamic response. Specifically, if the cardiac output is sufficiently improved, this might compensate for any increased desaturation and result in increased tissue oxygen delivery. This physiologic scenario does have implications for the performance and interpretation of the 6MWT (discussed below). The potential increased oxygen delivery also highlights the potential appeal of using the mixed venous oxygen saturation $(\mathrm{SpO} 2)$ as a study secondary end point, which would, of course, necessitate a baseline and follow-up right heart catheterization.

The exclusion of those patients who have worsened V/Q matching might be an attractive option since this might prime the population for success by eliminating a group who might do worse on therapy. This raises the notion of an adaptive trial design and the question of whether these patients can be identified and excluded during the screening phase or the baseline visit. Thus, for example, if all patients were administered a one-time dose of the therapy with a preand posttreatment evaluation of their oxygen needs, those deemed to have worsened oxygenation could be excluded. While multiple inert gas elimination technology is the best gauge of increased V/Q mismatching, this is not readily available and is logistically challenging. ${ }^{31} \mathrm{~A}$ simple gauge might be arterial blood gas and/or 6MWT comparison preand posttest dose. Whether or not a surrogate pulmonary vasodilator, such as inhaled nitric oxide (NO) could be used as a screen for other agents will require further study. Inhaled NO will likely not suffice as not all pulmonary vasodilators act the same, and certainly, there are bound to be different responses based on the mode of drug delivery (eg, inhaled versus oral therapy).

\section{End points in IPF PH studies}

The choice or crafting of a robust end point is another integral component of any study of PH therapy for IPF. The choice of end points employed in therapeutic trials for both IPF and PAH have been the subject of much debate and controversy. ${ }^{32,33}$ Being that the therapy being studied is a pulmonary vasoactive agent, the bias should be more toward a PAH end point. At the same time, disease progression from the IPF should be accounted for since this might impact the $\mathrm{PAH}$ end point. If the agent does not have any antifibrotic activity or does not accelerate the fibrotic process, then there would likely be equipoise between the two study arms. If PH has clinical consequences and the trial agent moderates the $\mathrm{PH}$, then the impact of this intervention should be captured through end points that evaluate functional ability, quality of life, hospitalization, or mortality. Which of these is the best primary end point or is it a composite of these that best captures the global impact of a $\mathrm{PH}$ intervention? While hemodynamic measurements before and after therapy would be interesting to provide physiologic plausibility, a reduction in mPAP and improvement in other hemodynamic variables does not necessarily translate to improved outcomes. Hemodynamic measurements may have a pivotal role in 
Phase I studies but in Phase II and III studies, should only be employed as secondary end points, complimenting the patients' primary outcome measures.

\section{The six-minute walk test}

The 6MWT has traditionally been used in all the PAH studies to date. ${ }^{34}$ Indeed, most of the nine available compounds for treatment of PAH have been approved based solely on differences in the change in the 6MWT between the treatment and placebo arms of the respective randomized controlled trials. Therefore, this simple functional test has been invaluable in enabling the approval of multiple PAH medications, which few will argue have changed the course and natural history of this previously universally fatal disease. However, the 6MWT has recently been critiqued and discredited as a surrogate for subsequent outcomes. ${ }^{34-36}$ This argument has been fueled based on the lack of association between the change in the 6WMT and subsequent outcomes. In the PAH arena, there has been a tide of sentiment that more robust end points, such as time to clinical worsening, be utilized. ${ }^{37}$ While there might be some merit to this, it is the authors' opinion that there is still a place and role for the 6MWT in clinical trials of both PAH and PH complicating IPF. Indeed, incorporated within most definitions of time to clinical worsening, is a categorical change in the 6MWT, and it is this component of the time to clinical worsening end point that constitutes the majority of events. Could and should the standard 6MWT be improved in its performance characteristics? Undoubtedly "yes". ${ }^{38}$ Issues to consider for modification include the performance of a training 6MWT and at least two tests to define the baseline. Should it be the greatest distance attained or the average of the distances that define the baseline? How close in distance should the two (or more) tests be to provide assurance of minimal intrapatient variability. Should it be a requirement that all patients complete a course of Pulmonary Rehabilitation prior to study entry to ensure that increased activity and exercise do not contribute to maintenance or improvement in the 6MWT? What of an upper and lower limit to the 6MWT distance as a study inclusion criterion? An upper limit eliminates the possibility of a "ceiling" effect that might "hide" a positive benefit of the study agent, while a lower limit serves to exclude the sickest patients who might be "too sick" for enrollment. For any study of a relatively rare entity, such as $\mathrm{PH}$ complicating IPF, it behooves the study design to have inclusionary criteria as broad as possible to facilitate study enrollment. Therefore, we favor a wide range for the baseline 6MWT and even suggest not mandating a 6MWT range for inclusion. What of the performance of the test itself? The American Thoracic Society (ATS) guidelines for the 6MWT are somewhat dated and were geared mostly towards patients with chronic obstructive pulmonary disease (COPD) ${ }^{39}$ The only output from this test, as described by the ATS is the distance attained. There is a growing body of literature attesting to other valuable parameters that can be derived during the course of the 6MWT, such as oxygen desaturation, the Borg score, the distance-saturation product, and pulse rate recovery. ${ }^{40-44}$ In terms of standardizing the performance of the test, there is, similarly, room for improvement. The amount of oxygen employed during the course of the test requires better specification and definition. While there is no "right" amount, it is clear that from the standpoint of a clinical trial where each patient functions as their own control, individual patients should walk on the same consistent amount of oxygen for every 6MWT throughout the course of the study. Oxygen is an agent that will alleviate pulmonary vasoconstriction and abrogate desaturation. Therefore any change in the concentration of this agent during the course of serial 6MWTs will have the ability to modulate differences in the distances attained. Each 6MWT should be performed with the standard menu of instructions and encouragement. Patients are specifically instructed to "walk as far as you can" in 6 minutes. No further prompting is allowed, and the effort and distance is dependent on the individual patient's interpretation of this instruction. A recent paper demonstrated in a prospective fashion that changing one word of this instruction, specifically, substituting "far" for "fast", resulted in a 50-meter increase in the distance attained. ${ }^{45}$ Therefore, somewhat paradoxically, if we wish for patients to walk as far as they can, then the best instruction to enable this might be to tell them to walk as fast as they can. It makes intuitive sense that the greater the effort and the closer to a maximal performance, the more likely intrapatient variability will be reduced. Improving the precision of the test might make the 6MWT distance a more accurate predictor of subsequent outcomes. Another issue that arises is that of safety and having a "stop" criterion for a low $\mathrm{SpO} 2$ level. There is no mention of this in the ATS statement, the implication being that patients would self-limit their walk before severe oxygen desaturations would occur. While this might be true for COPD patients, who generally have more ventilatory limitations, the same is not true for IPF patients, especially those with complicating $\mathrm{PH}$, who have a much greater propensity to desaturate. A low $\mathrm{SpO} 2$ safety threshold of $<80 \%$ has been instituted in previous IPF trials, but this has not been tested or validated as a necessary safety measure. The drawback of such a stop criterion is that it introduces the risk of a saturationlimited 6MWT distance. This might prevent a patient from demonstrating benefit with a greater walk distance, albeit at the cost of a lower $\mathrm{SpO} 2$. This dovetails with the pathophysiologic scenario outlined previously, which details how a patient with 
increased V/Q mismatching might still have a positive benefit from pulmonary vasoactive agents.

\section{Patient reported outcomes}

In terms of regulatory approval, agencies such as the Federal Drug Administration endorse end points that impact on how patients "feel", "function", and survive. Therefore the role and importance of patient-reported outcomes that provide a subjective serial assessment of patients' quality of life are being increasingly recognized for their importance. The ones that will ultimately prove useful in the context of PH/IPF studies remain to be determined, but it is likely that there are many instruments that can be used. These include the Saint George's respiratory questionnaire (SGRQ) and the modified version for IPF (SGRQ-I), the University of California, San Diego (UCSD) Shortness of Breath Questionnaire, as well as others. ${ }^{46-48}$ In patients with IPF/PH, who are invariably more symptomatic, these patient-reported outcomes might indeed prove to be very useful, especially as an adjunct or confirmation of changes in the 6MWT. On the other hand, it is also conceivable that patients might have worse $6 \mathrm{MWT}$ distances in the context of a saturation-limited study but an improved quality of life. Such discordance will need to be interpreted in the context of other available outcomes information.

\section{Hospitalization}

Hospitalization is an important event in both IPF as well as PAH and has been utilized as a component of composite end points in studies of both diseases. ${ }^{49,50}$ There is a school of thought that only hospitalization and mortality should be regarded as suitable end points for IPF clinical trials. ${ }^{51}$ However, if hospitalization is utilized as an end point, it is unclear whether this should be any (all-cause) hospitalization or more specifically, hospitalizations related to disease progression?

For IPF patients, hospital admissions may be regarded as a composite between respiratory events and nonrespiratory events. In the context of IPF complicated by PH, a further category might be cardiovascular admissions for those patients who are admitted with decompensated heart failure. Respiratory and cardiovascular admissions can be considered together under "cardiopulmonary admissions"; however, this might then capture other cardiac events, such as acute myocardial infarcts or arrhythmias. Therefore disease-specific hospitalizations might best be represented by admissions due to "worsening of disease".

The advantage of using all-cause hospitalizations as an end point is that this is a finite end point that does not require any adjudication. However, it appears that the inherent problems of this approach might outweigh any benefits of its ease and simplicity. It is conceivable that the majority of the events might not be due to disease worsening, in which case it would be without merit to judge a drug's efficacy based on events that are unrelated to its action. Indeed, a positive result might be hidden in the context of the all-cause hospitalization composite. As an example, if there were 400 study patients split equally between study drug and placebo arms and there were equivalent (eg, 50) hospitalization events in each group, there would be no difference in outcomes based on all-cause hospitalization in this hypothetical situation $(P=1.0$, Fisher's exact test). However, if within the study drug group there were five disease-worsening events and 45 nonrespiratory events, and within the placebo arm there were 25 disease-worsening events and 25 nonrespiratory events, then comparison of only the disease-worsening hospitalizations would yield a $P$-value of 0.0002 (Fisher's exact test). The investigational agent might be deemed to be ineffective based on the study end point of all-cause, nonelective hospitalizations, and its development may be halted on this basis. What could explain the placeboadjusted 20 nonrespiratory hospital admissions? An example might be a drug that causes gastrointestinal side effects or transient hypotension, the most severe of which warrant hospital admission. However, it is possible that the side-effect profile might have ultimately been shown to be transient and acceptable in the context of an effective drug for a deadly disease.

If a drug were to modulate the course of the disease, then it is a reasonable expectation that it might impact the subsequent need for respiratory admissions but not necessarily all-cause admissions. Respiratory hospitalizations may be a more robust and meaningful end point since such admissions have a stonger association with worse outcomes, compared to all-cause hospitalizations. ${ }^{23}$ There are issues, too, with using respiratory or disease-worsening hospitalizations; specifically, these can be difficult to discern, especially for patients with more advanced disease and for those admitted to remote hospitals. There are often grey zones in distinguishing a respiratory or diseaseworsening hospitalization from a nonrespiratory indication. For example, an IPF patient on 6 liters of oxygen might present to hospital with an unrelated issue (eg, a urinary tract infection) but be admitted for being so "sick" - in other words, admitted, not due to, but because of the IPF. A compromise perhaps is not hospital admission for cardiopulmonary worsening but rather, "the need for hospitalization". This caveat may allow patients who did not warrant admission to be weeded out. Similarly, those patients who do warrant but who decline admission can also then be captured. An example of the latter situation is a patient who elects to go on hospice care. 
Another issue that arises with regards to multicenter, multinational IPF studies is that thresholds for hospitalization may differ amongst providers, regions, and countries. Perhaps a compromise in terms of study design would be to define the criteria that warrant hospitalization, in an attempt to standardize this end point.

In summary, while hospitalization events may well be a valid end point in terms of being an important patientcentered outcome as well as a surrogate for mortality, there are many nuances that need to be considered, depending on the nature of the drug and the study population.

\section{Need for other PH therapy}

Although there are no approved medications for $\mathrm{PH}$ complicating IPF, there are cases in which the treating physician might feel that it is unethical to withhold PH therapy. Such situations might arise with those patients who develop clinical evidence of worsening right heart failure or who have an unfavorable hemodynamic profile on right heart catheterization, such as a low cardiac index and/or an elevated right atrial pressure. It is difficult to implement "need for PH therapy" as an end point since this might tacitly endorse the use of $\mathrm{PH}$ escape therapies. It is hoped that in such situations, these patients would be captured by one of the other proposed end points, such as hospitalization or change in the 6MWT distance.

\section{Change in functional class}

Functional class (FC) is a rather "blunt" subjective instrument that is subject to intraobserver variability. ${ }^{52}$ Nonetheless, the New York Heart Association FC and the modified WHO FC have been used as secondary end points in many PAH studies. These have also been used as part of composite end points, where they might have a useful complimentary role. Thus, for example, it could transpire that a patient worsens and after entering hospice care, cannot return to the study site for an evaluation of other objective measures of clinical worsening; this event might be captured through a telephone call, during which an assessment of the FC can be made.

\section{Lung transplantation}

Lung transplantation is certainly a very important end point for individual patients, but this does not necessarily translate into a useful end point in the context of clinical trials for IPF-related PH. There are a number of issues that limit its utility as an end point. First, not all patients are lung transplant candidates, and this is typically reserved for younger patients without any significant comorbidities. This will introduce inherent bias whereby some patients might have this available as an end point whereas other patients in the trial may not. The length of time on the list, as well as how "sick" patients might be when they receive the transplant, differs regionally as well as internationally, where different allocation systems are in place. Transplant-free survival has been used in some analyses and might be a reasonable end point since exclusion of transplant recipients from a survival analysis, too, introduces tremendous potential for bias.

\section{Mortality}

Mortality as the primary end point for studies of IPF in patients with mild to moderate disease are likely not feasible. ${ }^{53}$ However, in IPF patients with complicating $\mathrm{PH}$, this might indeed be realistic owing to the associated poor prognosis. The issue of whether or not this should be allcause mortality or cardiopulmonary mortality is a subject for some debate. All-cause mortality is most accepted as this is irrefutable and avoids any need for adjudication, which could be difficult given the paucity of data that, in many cases, accompanies the patient's demise.

\section{Composite end points}

The use of a composite end point in the context of an IPF-PH study enables disease worsening to be captured through one of a number of objective measures. ${ }^{54}$ It might, however, be difficult to discern whether worsening is due to the $\mathrm{PH}$ or pulmonary fibrosis component of the patient's disease, but this is arguably semantic. Certainly, the pulmonary fibrosis component might be driving the worsening in some of the cases, and the PH medication might not have any impact on this - the key to limiting these events is in the patient selection process, whereby the study population should select for those likely to have worsening due to their PH. No matter how robust the inclusion criteria are in this regard, undoubtedly there will be some patients with worsening parenchymal disease. However, it is hoped that the randomization process will maintain equipoise between the two groups in this regard. An example of some of the end points that could be used as components of a composite is shown in Figure 1.

\section{Summary}

There is good biologic and physiologic rationale as well as outcomes data to support studies addressing PH complicating IPF. There are many elements that are integral to a successful study: a drug that works, administration of the drug at an appropriate dose, a well-targeted patient cohort that is followed long enough to see an effect, and a carefully constructed end point. If all such elements are aligned, a positive study of 


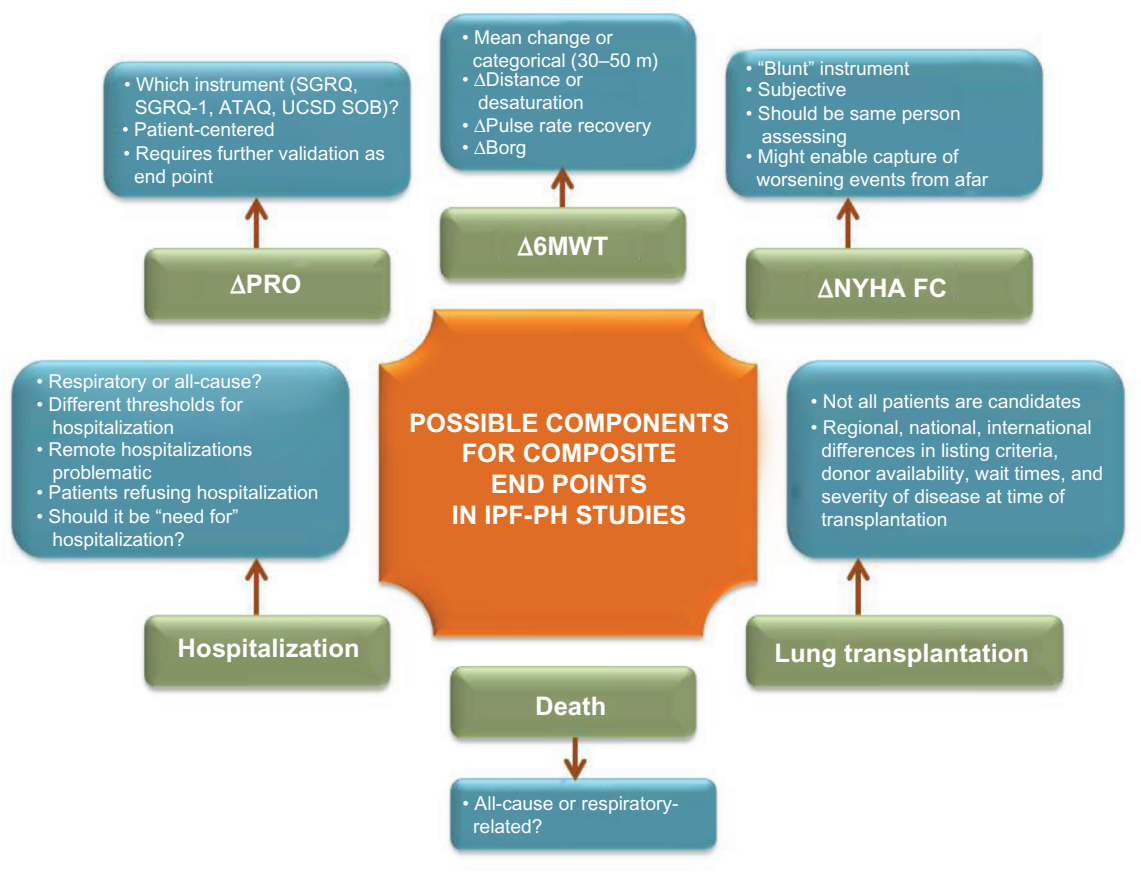

Figure I A summary of end points that may be used in IPF-PH clinical trials.

Abbreviations: ATAQ, IPF-specific quality of life questionnaire; Borg, Borg dyspnea score; IPF, idiopathic pulmonary fibrosis; NYHA FC, New York Heart Association functional class; PH, pulmonary hypertension; PRO, patient-reported outcomes; SGRQ, Saint George's Respiratory Questionnaire; SGRQ-I, modified SGRQ, for IPF; USCD SOB, University of California, San Diego Shortness of Breath Questionnaire; 6MWT, six-minute walk test.

a pulmonary vasoactive agent might indeed demonstrate an important aspect of IPF to be targeted.

\section{Disclosure}

Dr Nathan has received research funding and/or has consulted for Actelion, Boerhinger-Ingelheim, Bayer Pharmaceuticals, Gilead Sciences, Intermune, Roche, and United Therapeutics on the subjects of IPF and pulmonary hypertension. The authors report no other conflicts of interest in this work.

\section{References}

1. Nathan SD, Hassoun PM. Pulmonary hypertension due to lung disease and/or hypoxia. Clin Chest Med. 2013;34(4):695-705.

2. Simonneau G, Gatzoulis MA, Adatia I, et al. Updated clinical classification of pulmonary hypertension. J Am Coll Cardiol. 2013;62(Suppl 25): D34-D41.

3. Nathan SD, Noble PW, Tuder RM. Idiopathic pulmonary fibrosis and pulmonary hypertension: connecting the dots. Am J Respir Crit Care Med. 2007;175(9):875-880.

4. Ley B, Collard HR. Epidemiology of idiopathic pulmonary fibrosis. Clin Epidemiol. 2013;5:483-492.

5. King C, Nathan SD. Identification and treatment of comorbidities in idiopathic pulmonary fibrosis and other fibrotic lung diseases. Curr Opin Pulm Med. 2013;19(5):466-473.

6. Panos RJ, Mortenson RL, Niccoli SA, King TE. Clinical deterioration in patients with idiopathic pulmonary fibrosis: causes and assessment. Am J Med. 1990;88(4):396-404.

7. Nathan SD, Shlobin OA, Weir N, et al. Long-term course and prognosis of idiopathic pulmonary fibrosis in the new millennium. Chest. 2011;140(1):221-229.
8. Lettieri CJ, Nathan SD, Barnett SD, Ahmad S, Shorr AF. Prevalence and outcomes of pulmonary arterial hypertension in advanced idiopathic pulmonary fibrosis. Chest. 2006;129(3):746-752.

9. Nadrous HF, Pellikka PA, Krowka MJ, et al. Pulmonary hypertension in patients with idiopathic pulmonary fibrosis. Chest. 2005;128(4): 2393-2399.

10. Song JW, Song JK, Kim DS. Echocardiography and brain natriuretic peptide as prognostic indicators in idiopathic pulmonary fibrosis. Respir Med. 2009;103(2):180-186.

11. Sherner J, Collen J, King CS, Nathan SD. Pulmonary hypertension in idiopathic pulmonary fibrosis: epidemiology, diagnosis and therapeutic implications. Curr Respir Care Rep. 2012;1:233-242.

12. Nathan SD, Shlobin OA, Ahmad S, Urbanek S, Barnett SD. Pulmonary hypertension and pulmonary function testing in idiopathic pulmonary fibrosis. Chest. 2007;131(3):657-663.

13. Zisman DA, Karlamangla AS, Ross DJ, et al. High-resolution chest CT findings do not predict the presence of pulmonary hypertension in advanced idiopathic pulmonary fibrosis. Chest. 2007;132(3): 773-779.

14. Krowka MJ, Ahmad S, de Andrade JA, et al. A Randomized, doubleblind, placebo-controlled study to evaluate the safety and efficacy of iloprost inhalation in adults with abnormal pulmonary arterial pressure and exercise limitation associated with idiopathic pulmonary fibrosis [abstract]. Chest. 2007;132(4 MeetingAbstracts):633a-633.

15. Zisman DA, Schwarz M, Anstrom KJ, Collard HR, Flaherty KR, Hunninghake GW; Idiopathic Pulmonary Fibrosis Clinical Research Network. A controlled trial of sildenafil in advanced idiopathic pulmonary fibrosis. N Engl J Med. 2010;363(7):620-628.

16. Ghofrani HA, Wiedemann R, Rose F, et al. Sildenafil for treatment of lung fibrosis and pulmonary hypertension: a randomised controlled trial. Lancet. 2002;360(9337):895-900.

17. Collard HR, Anstrom KJ, Schwarz MI, Zisman DA. Sildenafil improves walk distance in idiopathic pulmonary fibrosis. Chest. 2007;131(3): 897-899.

18. Günther A, Enke B, Markart P, et al. Safety and tolerability of bosentan in idiopathic pulmonary fibrosis: an open label study. Eur Respir J. 2007;29(4):713-719. 
19. Jackson RM, Glassberg MK, Ramos CF, Bejarano PA, Butrous G, Gómez-Marín O. Sildenafil therapy and exercise tolerance in idiopathic pulmonary fibrosis. Lung. 2010;188(2):115-123.

20. King TE, Behr J, Brown KK, et al. BUILD-1: a randomized placebocontrolled trial of bosentan in idiopathic pulmonary fibrosis. Am J Respir Crit Care Med. 2008;177(1):75-81.

21. Raghu G, Behr J, Brown KK, et al; ARTEMIS-IPF Investigators*. Treatment of idiopathic pulmonary fibrosis with ambrisentan: a parallel, randomized trial. Ann Intern Med. 2013;158(9):641-649.

22. Raghu G, Million-Rousseau R, Morganti A, Perchenet L, Behr J; MUSIC Study Group. Macitentan for the treatment of idiopathic pulmonary fibrosis: the randomised controlled MUSIC trial. Eur Respir J. 2013;42(6):1622-1632.

23. Han MK, Bach DS, Hagan PG, et al; IPFnet Investigators. Sildenafil preserves exercise capacity in patients with idiopathic pulmonary fibrosis and right-sided ventricular dysfunction. Chest. 2013;143(6): 1699-1708.

24. Seeger W, Adir Y, Barberà JA, et al. Pulmonary hypertension in chronic lung diseases. J Am Coll Cardiol. 2013;62(25 Suppl D):D109-D116.

25. Nathan SD, Shlobin OA, Barnett SD, et al. Right ventricular systolic pressure by echocardiography as a predictor of pulmonary hypertension in idiopathic pulmonary fibrosis. Respir Med. 2008;102(9):1305-1310.

26. Chin KM, Kim NH, Rubin LJ. The right ventricle in pulmonary hypertension. Coron Artery Dis. 2005;16(1):13-18.

27. Haddad F, Doyle R, Murphy DJ, Hunt SA. Right ventricular function in cardiovascular disease, part II: pathophysiology, clinical importance, and management of right ventricular failure. Circulation. 2008;117(13): $1717-1731$.

28. Saggar R, Khanna D, Vaidya A, et al. Changes in right heart haemodynamics and echocardiographic function in an advanced phenotype of pulmonary hypertension and right heart dysfunction associated with pulmonary fibrosis. Thorax. 2014;69(2):123-129.

29. Hamada K, Nagai S, Tanaka S, et al. Significance of pulmonary arterial pressure and diffusion capacity of the lung as prognosticator in patients with idiopathic pulmonary fibrosis. Chest. 2007;131(3):650-656.

30. Nathan SD, Shlobin OA, Ahmad S, et al. Serial development of pulmonary hypertension in patients with idiopathic pulmonary fibrosis. Respiration. 2008;76(3):288-294.

31. Wagner PD. The multiple inert gas elimination technique (MIGET). Intensive Care Med. 2008;34(6):994-1001.

32. Snow JL, Kawut SM. Surrogate End Points in Pulmonary Arterial Hypertension: Assessing the Response to Therapy. Clin Chest Med. 2007;28(1):75-viii.

33. Albera C. Challenges in idiopathic pulmonary fibrosis trials: the point on end-points. Eur Respir Rev. 2011;20(121):195-200.

34. Farber HW. Validation of the 6-minute walk in patients with pulmonary arterial hypertension: trying to fit a square PEG into a round hole? Circulation. 2012;126(3):258-260.

35. Gabler NB, French B, Strom BL, et al. Validation of 6-minute walk distance as a surrogate end point in pulmonary arterial hypertension trials. Circulation. 2012;126(3):349-356.

36. Savarese G, Paolillo S, Costanzo P, et al. Do changes of 6-minute walk distance predict clinical events in patients with pulmonary arterial hypertension? A meta-analysis of 22 randomized trials. $J$ Am Coll Cardiol. 2012;60(13):1192-1201.

37. Gomberg-Maitland M, Bull TM, Saggar R, et al. New trial designs and potential therapies for pulmonary artery hypertension. $\mathrm{J} \mathrm{Am} \mathrm{Coll}$ Cardiol. 2013;62(Suppl 25):D82-D91.

38. Dolmage TE, Hill K, Evans RA, Goldstein RS. Has my patient responded? Interpreting clinical measurements such as the 6-minutewalk test. Am J Respir Crit Care Med. 2011;184(6):642-646.
39. ATS Committee on Proficiency Standards for Clinical Pulmonary Function Laboratories. ATS statement: guidelines for the six-minute walk test. Am J Respir Crit Care Med. 2002;166(1):111-117.

40. Lama VN, Flaherty KR, Toews GB, et al. Prognostic value of desaturation during a 6-minute walk test in idiopathic interstitial pneumonia. Am J Respir Crit Care Med. 2003;168(9):1084-1090.

41. Lettieri CJ, Nathan SD, Browning RF, Barnett SD, Ahmad S, Shorr AF. The distance-saturation product predicts mortality in idiopathic pulmonary fibrosis. Respir Med. 2006;100(10):1734-1741.

42. Swigris JJ, Wamboldt FS, Behr J, et al. The 6 minute walk in idiopathic pulmonary fibrosis: longitudinal changes and minimum important difference. Thorax. 2010;65(2):173-177.

43. Swigris JJ, Swick J, Wamboldt FS, et al. Heart rate recovery after 6-min walk test predicts survival in patients with idiopathic pulmonary fibrosis. Chest. 2009;136(3):841-848.

44. Swigris JJ, Olson AL, Shlobin OA, Ahmad S, Brown KK, Nathan SD. Heart rate recovery after six-minute walk test predicts pulmonary hypertension in patients with idiopathic pulmonary fibrosis. Respirology. 2011;16(3):439-445.

45. Weir NA, Brown AW, Shlobin OA, et al. The influence of alternative instruction on 6-min walk test distance. Chest. 2013;144(6): 1900-1905.

46. Swigris JJ, Fairclough D. Patient-reported outcomes in idiopathic pulmonary fibrosis research. Chest. 2012;142(2):291-297.

47. Yorke J, Jones PW, Swigris JJ. Development and validity testing of an IPF-specific version of the St George's Respiratory Questionnaire. Thorax. 2010;65(10):921-926.

48. Swigris JJ, Wilson SR, Green KE, Sprunger DB, Brown KK, Wamboldt FS. Development of the ATAQ-IPF: a tool to assess quality of life in IPF. Health Qual Life Outcomes. 2010;8:77.

49. Noth I, Anstrom KJ, Calvert SB, et al; Idiopathic Pulmonary Fibrosis Clinical Research Network (IPFnet). A placebo-controlled randomized trial of warfarin in idiopathic pulmonary fibrosis. Am J Respir Crit Care Med. 2012;186(1):88-95.

50. Pulido T, Adzerikho I, Channick RN, et al; SERAPHIN Investigators. Macitentan and morbidity and mortality in pulmonary arterial hypertension. N Engl J Med. 2013;369(9):809-818.

51. Raghu G, Collard HR, Anstrom KJ, et al. Idiopathic pulmonary fibrosis: clinically meaningful primary endpoints in phase 3 clinical trials. $\mathrm{Am}$ $J$ Respir Crit Care Med. 2012;185(10):1044-1048.

52. Taichman DB, McGoon MD, Harhay MO, et al. Wide variation in clinicians' assessment of New York Heart Association/World Health Organization functional class in patients with pulmonary arterial hypertension. Mayo Clin Proc. 2009;84(7):586-592.

53. King TE, Albera C, Bradford WZ, et al. All-cause mortality rate in patients with idiopathic pulmonary fibrosis. Implications for the design and execution of clinical trials. Am J Respir Crit Care Med.2014;189(7): 825-831.

54. Kaul S, Diamond GA. Trial and error. How to avoid commonly encountered limitations of published clinical trials. J Am Coll Cardiol. 2010;55(5):415-427.

55. Minai OA, Sahoo D, Chapman JT, Mehta AC. Vaso-active therapy can improve 6-min walk distance in patients with pulmonary hypertension and fibrotic interstitial lung disease. Respir Med. 2008;102(7): $1015-1020$.

56. Raghu G, King TE Jr, Behr J, et al. Quality of life and dyspnoea in patients treated with bosentan for idiopathic pulmonary fibrosis (BUILD-1). Eur Respir J. 2010;35(1):118-123.

57. King TE, Brown KK, Raghu G, et al. BUILD-3: a randomized, controlled trial of bosentan in idiopathic pulmonary fibrosis. Am J Respir Crit Care Med. 2011;184(1):92-99. 


\section{Publish your work in this journal}

Drug Design, Development and Therapy is an international, peerreviewed open-access journal that spans the spectrum of drug design and development through to clinical applications. Clinical outcomes, patient safety, and programs for the development and effective, safe, and sustained use of medicines are a feature of the journal, which has also been accepted for indexing on PubMed Central. The manuscript management system is completely online and includes a very quick and fair peer-review system, which is all easy to use. Visit http://www.dovepress.com/testimonials.php to read real quotes from published authors.

Submit your manuscript here: http://www.dovepress.com/drug-design-development-and-therapy-journal 